\title{
Precursors to language: Social cognition and pragmatic inference in primates
}

\author{
Robert M. Seyfarth ${ }^{1}$ - Dorothy L. Cheney ${ }^{2}$
}

Published online: 1 July 2016

(C) Psychonomic Society, Inc. 2016

\begin{abstract}
Despite their differences, human language and the vocal communication of nonhuman primates share many features. Both constitute forms of coordinated activity, rely on many shared neural mechanisms, and involve discrete, combinatorial cognition that includes rich pragmatic inference. These common features suggest that during evolution the ancestors of all modern primates faced similar social problems and responded with similar systems of communication and cognition. When language later evolved from this common foundation, many of its distinctive features were already present.
\end{abstract}

Keywords Evolution · Language/memory interactions ·

Social cognition $\cdot$ Nonhuman primates

Human language poses a problem for evolutionary theory because of the striking discontinuities between language and the communication of our closest animal relatives, the nonhuman primates. How could language have evolved from the common ancestor of these two very different systems?

The qualitative differences between language and nonhuman primate communication are well known (Fitch, 2010). All languages are built up from a large repertoire of learned, modifiable sounds. These sounds are combined into syllables, which are combined into words, which in turn are combined according to grammatical rules into sentences. In sentences,

Robert M. Seyfarth

seyfarth@psych.upenn.edu

1 Department of Psychology and Institute for Research in Cognitive Science, University of Pennsylvania, Philadelphia, PA, USA

2 Department of Biology and Institute for Research in Cognitive Science, University of Pennsylvania, Philadelphia, PA, USA the meaning of each word derives both from its own, standalone meaning and from its functional role as a noun, verb, or modifier. Grammatical rules allow a finite number of elements to convey an infinite number of meanings: The meaning of a sentence is more than just the summed meanings of its constituent words. Languages derive their communicative power from being discrete, combinatorial, rule-governed, and openended computational systems (Jackendoff, 1994; Pinker, 1994).

By contrast, nonhuman primates (prosimians, monkeys, and apes) - and indeed most mammals - have a relatively small repertoire of calls. Their vocalizations exhibit only slight modification during development (Hammerschmidt \& Fischer, 2008), and although animals can give or withhold calls voluntarily and modify the timing of vocal production (Seyfarth \& Cheney, 2010), different call types are rarely given in combinations (but see Shlenker et al., 2016). When call combinations do occur, there is little evidence that individual calls play functional roles as agents, actions, or patients. As a result, primate vocalizations, when compared to language, are believed to convey only limited information (Bickerton, 1990; Fitch, 2010; Hurford, 2007).

The differences between human language and nonhuman primate communication are clearest in call production. Continuities are more apparent, however, when one considers the underlying neural mechanisms that govern call perception, the complex pragmatic inferences that listeners make when interpreting calls, and the function of vocal signals in the daily lives of individuals. Here we focus on nonhuman primates as perceivers, and on the perceptual and cognitive mechanisms that underlie their responses to signals. In these contexts, we argue that human and nonhuman primates exhibit many homologous brain mechanisms that have evolved to serve similar social functions. We suggest that vocalizations and social knowledge combine to form a system of communication that, 
in its underlying perception and cognition, is discrete, combinatorial, rule-governed, and open-ended. It also relies on a rich system of knowledge derived from the social context, or pragmatic inference. We conclude that, long before language evolved, a discrete, combinatorial system of communication, perception, and cognition - with many of language's supposedly unique features - was already in place in primate receivers.

\section{Homologous neural mechanisms}

Human and nonhuman primates share many neurological mechanisms for perceiving, processing, and responding to communicative signals. These include mechanisms for the recognition of faces (Freiwald, Tsao, \& Livingston, 2009; Kanwisher, McDermott, \& Chun, 1997; Tsao, Freiwald, Tootell, \& Livingston, 2006) and voices (Belin \& Zattore, 2003; Petkov et al., 2008), for the processing of auditory sequences (Wilson et al., 2015), and for the multisensory integration of bimodal stimuli, specifically voices and concurrent facial expressions (Ghazanfar \& Eliades, 2014). In both humans and macaques, neurons in the ventral premotor cortex exhibit neural activity both when performing a specific action and when observing another perform the same action (de Waal \& Ferrari, 2010; Ferrari, Bonini, \& Fogassi, 2009). Moreover, in both humans and macaques the ventrolateral prefrontal cortex plays an important role in the classification of conspecific calls with different acoustic properties that either are or are not associated with the same events (Gifford, MacLean, Hauser, \& Cohen, 2005).

These shared mechanisms are unlikely to have arisen by accident. Instead, it seems likely that during their common evolutionary history (from roughly 30 to 5 million years ago: Steiper, Young, \& Sukarna, 2004) Old World monkeys, apes, and early hominids faced similar problems in communication and evolved similar mechanisms to deal with them. The more recent evolution of language in the human lineage (during the past 5-6 million years: Glazko \& Nei, 2003) built upon these shared mechanisms. What were these common communicative problems?

\section{Similar social functions}

Clark (1996) examined language as a form of coordinated activity, used by people in face-to-face interactions to facilitate their activities. He emphasized that language users are not "generic speakers and addressees, but real people, with identities, genders, histories, personalities, and names" (p.xi). Clark's analysis is important because, unlike discussions that emphasize language's formal semantic and syntactic structures, it focuses on how language functions in the daily social life of individuals, many of whom have a long history of past interaction. Clark therefore provides an ideal background against which to compare the social function of language with the social function of vocalizations in nonhuman primate groups. Here we make such a comparison, drawing on recent research with wild baboons. We suggest that language and nonhuman primate communication, superficially so different, share many functions. These shared functions help explain the evolution of the homologous neural mechanisms listed above.

Baboons live throughout the savannah woodlands of Africa in groups of 50 to 150 individuals. Although most males emigrate to other groups as young adults, females remain in their natal groups throughout their lives, maintaining close social bonds with their matrilineal kin. Females can be ranked in a stable, linear dominance hierarchy that determines priority of access to resources. Daughters acquire ranks similar to those of their mothers. The stable core of a baboon group is therefore a hierarchy of matrilines, in which all members of one matriline (e.g., matriline B) outrank or are outranked by all members of another (e.g., matrilines $\mathrm{C}$ and $\mathrm{A}$, respectively). Ranks are extremely stable, often remaining unchanged for decades (Cheney \& Seyfarth, 2007; Silk, Altmann, \& Alberts, 2006a, 2006b). When rank reversals occur within a matriline, they affect only the two individuals involved. However, when rank reversals occur between individuals in different matrilines, most members of the lower-ranking matriline rise in rank together above all members of the previously higher-ranking matriline (Cheney \& Seyfarth, 2007). Figure 1 illustrates the matrilineal hierarchy found in a typical baboon group.

Baboon vocalizations are individually distinctive (Owren, Seyfarth, \& Cheney, 1997), and listeners recognize the voices of others as the calls of specific individuals (Cheney \& Seyfarth, 2007). The baboon vocal repertoire contains a number of acoustically graded signals, each of which is given in predictable contexts (Fischer, Metz, Cheney, \& Seyfarth, 2001). Grunts may be given to any other individual,

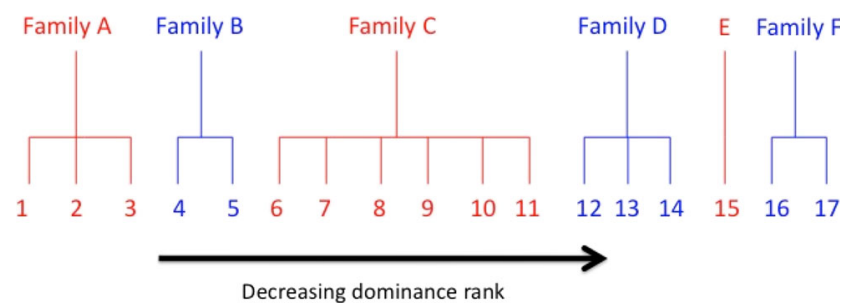

Fig. 1 The hierarchical organization of females and offspring in a typical baboon group. Matrilineal kin groups (mothers and offspring: "families") are denoted by letters and arranged from left to right in descending dominance rank order. Individuals within families are denoted by numbers and also arranged in descending rank order. Data are taken from Cheney and Seyfarth (2007). The figure is from "The Evolution of Language From Social Cognition," by Seyfarth and Cheney 2014b, Current Opinion in Neurobiology, 28, p. 6. Copyright 2014 by Elsevier B.V. Reprinted with permission. 
regardless of rank; threat-grunts are given only by higherranking to lower-ranking individuals; fear-barks and screams are given only by lower-ranking to higher-ranking individuals (Cheney \& Seyfarth, 2007).

Field playback experiments have demonstrated that the baboons' system of communication has the following properties:

An individual who hears a vocalization assesses the caller's intention to communicate to her. If two animals engage in aggression, then separate, and then one hears a threat-grunt from the other, the listener responds as if the threat is directed at her, but if the threat-grunt is heard after a recent grooming interaction, the listener responds as if the call is directed at another individual (Engh et al., 2006). Upon hearing a vocalization, therefore, a listener acts as if she assesses whether or not the call is directed at her: That is, she responds on the basis of her evaluation of the caller's intent to communicate.

Calls function to facilitate social interactions. Female baboons are strongly attracted to young infants, but the infants' mothers are often reluctant to have them touched or handled. Grunts facilitate infant handling: If a female gives a series of grunts as she approaches a mother with infant, the mother is significantly less likely to move away, and infant handling is more likely, than if the approaching female remains silent (Cheney, Seyfarth, \& Silk, 1995). How do grunts achieve this outcome? Studying rhesus macaques (Macaca mulatta), in which females' interest in infants is also high and grunts and girney vocalizations facilitate infant handling, Silk, Kaldor, and Boyd (2000) found that grunts and girneys accurately predicted the approaching female's subsequent behavior: If she vocalized, aggression was significantly less likely and grooming was significantly more likely than if she did not. As a result, there was a contingent, predictable relation between the approaching female's vocalizations and what she did next. Presumably, mothers recognized this contingency and treated grunts and girneys as honest indicators of the approaching female's benign disposition. Once again, listeners' responses depend on their judgments of the signaler's intentions.

Listeners assess the meaning of calls by integrating information from multiple sources: the call type, the caller's identity, previous events, and the caller's and listener's relationships with others. As background, recall that rank relations among females are generally stable over time, with few reversals occurring either within or between families. However, when reversals do occur, their consequences differ significantly depending on who is involved. For example, if the third-ranking female in matriline B (B3) rises in rank above her second-ranking sister (B2), the reversal affects only these two individuals. By contrast, a rank reversal between two females from different matrilines (e.g., $\mathrm{C} 1$ rising in rank above $\mathrm{B} 3$ ) potentially affects entire families, since all members of the $\mathrm{C}$ matriline are likely to rise above all the members of the B matriline (Cheney \& Seyfarth, 2007).

In one set of trials, the subjects heard an apparent rank reversal involving two members of the same matriline: for example, female B3 giving threat-grunts while female B2 screamed. Later, the same subjects heard an apparent rank reversal involving the members of two different matrilines: for example, female $\mathrm{C} 1$ giving threat-grunts while female B3 screamed. As a control, subjects heard a fight sequence that was consistent with the female dominance hierarchy. As in prior tests (Cheney et al., 1995), listeners responded with apparent surprise to call sequences that appeared to violate the existing dominance hierarchy, suggesting that their expectations included information about the "rules" of call delivery (see above) and the relative ranks of the individuals involved. In addition, between-family rank reversals elicited a consistently stronger response than did within-family rank reversals (Bergman, Beehner, Cheney, \& Seyfarth, 2003), suggesting that expectations also included information about matrilineal kinship and the nested relationship of kinship and rank (see also Schino, Tiddi, \& Polizzi di Sorrentino, 2006).

Other experiments have yielded similar results. After aggression between individuals from different matrilines (say, females C2 and D2), D2 responded to a grunt from $\mathrm{C} 2$ as if it signaled reconciliation. By contrast, playback of a grunt from another, higher-ranking individual not previously involved in an aggressive interaction with the victim produced no such changes in D2's behavior (Cheney \& Seyfarth, 1997). The grunts of a close relative of the aggressor can also reconcile opponents: Victims of aggression were more likely to tolerate their opponent's proximity in the hour after aggression if they heard the grunt of their opponent's relative than if they heard the grunt of a more dominant individual belonging to a different matriline (Wittig, Crockford, Ekberg, Seyfarth, \& Cheney, 2007). Similarly, after aggression between C2 and D2, D2 moved away from the speaker if she heard a threat-grunt from any of C2's close kin, treating this call as a sign of renewed aggression directed at her. By contrast, she showed no such response to threat-grunts from members of other matrilines (Wittig, Crockford, Seyfarth, \& Cheney, 2007). These responses did not occur because members of the same matriline sound alike: In other contexts, listeners were clearly able to distinguish between closely related females' calls. Instead, listeners' responses reflected their integration of information from the call type, the caller's identity and matrilineal kin group, and the listener's memory of previous interactions with the caller or the caller's kin. 


\section{Primate communication and cognition: A discrete, computational system}

Considered in isolation, baboon vocalizations are very general, nonspecific signals, broadly associated with affiliative behavior, aggression, fear, and alarm. Vocalizations, however, do not exist in a social vacuum. Each call occurs in circumstances in which the caller and recipient recognize each other, know about each other's relationships, and have a long history of interaction. When one animal vocalizes to another, the recipient is therefore free to supplement information acquired from the call itself with information acquired from the context - specifically her rich history of interaction with the caller and the caller's kin. Thanks to pragmatic inference, very general, nonspecific signals can convey highly specific information (Seyfarth \& Cheney 2016).

When a baboon hears a vocalization, she forms a mental representation of the call's meaning. This representation develops instantly and is built up from several discrete pieces of information: the type of call, the caller's identity, recent events, and the caller's dominance rank and kinship affiliation. When a listener hears two animals vocalizing to each other, the meaning of this sequence includes the representation of an actor who is performing a specific action on a recipient and causing the recipient's response: If there were no attribution of causality, there would be no violation of expectation when a lower-ranking animal threatens a higher-ranking animal and the latter screams; the calls would simply have occurred together by chance. For receivers, the discrete elements of call type, caller identity, and kin group are combined according to the rules of call delivery to create a message whose meaning is more than just the sum of the meanings of its constituent elements.

A baboon's assessment of call meaning thus constitutes a discrete, combinatorial, rule-governed, and open-ended system of communication (Cheney \& Seyfarth, 1998; Worden, 1998) in which the assessment of meaning depends upon the call type and pragmatic inference based on social knowledge. In baboon communication, moreover, a finite number of signals can yield a nearly infinite number of meanings. If a listener recognizes the difference between [A threatens $\mathrm{B}$ and $\mathrm{B}$ screams] and [B threatens A and A screams], and can make this distinction for every dyad in a group of 70-80 individuals, a simple system of signals can generate a huge number of meanings. Finally, the communicative system is effectively open-ended, because baboons learn to recognize the calls of new infants, new male immigrants - indeed any new individual-and assign meaning to these calls depending on the new individuals' ranks and kinship affiliations.

This does not mean that vocal communication in baboons constitutes a language, or even that baboon communication has many of language's formal semantic or syntactic properties (clearly it does not). Instead, we suggest that several of the cognitive mechanisms that have long been thought to mark a clear separation between language and nonhuman primate communication can, in fact, be found - in admittedly simpler form-in the communication and social cognition of nonhuman primates. As a result, the earliest steps toward the evolution of language may not be as difficult to imagine as originally thought (Pinker, 1994).

It seems likely that the rich system of pragmatic inference that we have documented among baboons will be found in other species, particularly those in which individuals live long lives, interact repeatedly with the same partners, and recognize each others' relationships. If this proves correct, and if we accept the idea that communication in modern monkeys and apes provides a rough guide to the prelinguistic communication of our hominid ancestors, then that ancestral communication would be characterized by a relatively small repertoire of calls, limited semantics and syntax, but a rich system of meanings based on social knowledge and pragmatic inference. This, in turn, would suggest that, as language evolved from its prelinguistic ancestors, the relatively later appearance of semantics and syntax was built upon a foundation of social cognition.

Why should nonhuman primates have evolved such a sophisticated system of social knowledge? Long-term field studies demonstrate that an important predictor of a baboon's or a chimpanzee's reproductive success is an individual's ability to form close, long-term bonds. Doing so, moreover, would seem to require recognition of the relationships that exist among others (Gilbey et al., 2013; Mitani, 2009; Silk et al., 2009,2010 ). Similar results apply to many nonprimate mammals (see Seyfarth \& Cheney, 2012, for a review). Long before the evolution of language, therefore, selection favored individuals who were skilled both in the use of communication to form and maintain bonds and in the cognitive skills needed to derive, from personal experience and eavesdropping, information about other animals' relationships. Long before language, therefore, selection favored discrete, combinatorial thinking and sophisticated pragmatic inference (Cheney \& Seyfarth, 2007; Seyfarth \& Cheney, 2014b).

\section{Social knowledge as a cognitive precursor to language}

In many respects this proposal is not new. For example, Hockett (1960) listed "discreteness" and "productivity" as two distinctive features of language that call for an evolutionary explanation, whereas Pinker and Bloom (1990) suggested that during the course of human evolution "grammar exploited mechanisms originally used for ... conceptualization" (Pinker \& Bloom, 1990, p. 713). Similarly, Newmeyer (1991, p. 10) argued that "the conditions for the subsequent development of 
language ... were set by the evolution of . . . conceptual structure. A first step toward the evolution of this system ... was undoubtedly the linking up of individual bits of conceptual structure to individual vocalizations" (see also Hurford, 2003; Jackendoff, 1987; Kirby, 1998). The present proposal is new, however, in its emphasis on social cognition (Worden, 1998, makes a similar argument), and because we can now link social cognition with reproductive success (Cheney \& Seyfarth, 1990, 2007; Gilbey et al., 2013; Silk et al., 2009, 2010).

Three sorts of cognition, all well-documented in animals, have been offered as possible precursors of language (Hauser, Chomsky, \& Fitch, 2002): orientation and navigation (e.g., Menzel, 2011), number (Cantlon \& Brannon, 2007), and social cognition (Cheney \& Seyfarth, 1990; Worden, 1998). All involve discrete elements and rule-governed computations. In three respects, however, social cognition seems the most likely candidate as a precursor of language. First, only in social cognition do the discrete elements include living creatures, to which listeners can reasonably attribute motives and goals, and context-specific vocalizations that are also associated with a caller's motivation to interact with another in specific ways. Only social cognition, therefore, deals with agents, actions, and patients (Seyfarth \& Cheney, 2014b).

Second, only in social cognition are the discrete elements explicitly linked to vocalizations, so that the system of communication and the system of cognition on which it is based are tightly coupled. This merging of communication and cognition does not occur in animal orientation, navigation, or systems of number.

Third, only in social cognition are the discrete elements linked - as in language - to the organization of items into concepts. Because the meaning of a baboon's call is inseparable from the identity of the caller, her dominance rank, and her family membership, baboon communication relies on a form of concept formation based on socially defined categories (Seyfarth \& Cheney, 2012, 2014a). The social categories of "kinship" and "dominance rank" qualify as concepts because they cannot be reduced to any one, or even a few, sensory attributes. Family members do not always look alike, sound alike, behave alike, or share any other physical or personality features that make them easy to classify together (Seyfarth \& Cheney, 2014b). Higher-ranking individuals do not differ in any physical respects from lower-ranking animals. Social categories also qualify as concepts because they persist despite changes in their composition. Among females and juveniles, the recognition of families is unaffected by births and deaths; among adult males, the recognition of a linear, transitive hierarchy persists despite frequent changes in the individuals who occupy each position (Kitchen, Cheney, \& Seyfarth, 2005). In the mind of a baboon, therefore, social categories exist independent of their members. And because the meaning of a vocalization cannot be divorced from the caller's identity, and the caller's identity cannot be separated from her placement in a conceptual structure based on kinship and rank, communication and conceptual structure are inextricably bound together-just as we might expect in a system of communication that served as a precursor to human language and thought.

\section{Conclusions}

Nonhuman primates live in complex social groups in which an individual's reproductive success depends on skills in forming strong social bonds and representing the relationships of others. In response, animals have evolved systems of communication and cognition that are discrete, combinatorial, rulegoverned, and open-ended. As a result, when language first evolved from the communication of nonhuman primates, many of its distinctive cognitive features were already in place.

Author note Research on baboons was supported by the National Science Foundation Grant No. 95-14001, National Institutes of Health Grant No. MH 62249, the National Geographic Society, the Leakey Foundation, and the University of Pennsylvania. We thank Delphine Dahan, Tecumseh Fitch, Daniel Swingley, John Trueswell, and two reviewers for comments.

\section{References}

Belin, P., \& Zattore, R. J. (2003). Adaptation to speaker's voice in right anterior temporal lobe. NeuroReport, 14, 2105-2109.

Bergman, T., Beehner, J. C., Cheney, D. L., \& Seyfarth, R. M. (2003). Hierarchical classification by rank and kinship in baboons. Science, 302, 1234-1236.

Bickerton, D. (1990). Language and species. Chicago: University of Chicago Press.

Cantlon, J. F., \& Brannon, E. (2007). Basic math in monkeys and college students. PLoS Biology, 5, e328.

Cheney, D. L., \& Seyfarth, R. M. (1990). How monkeys see the world. Chicago: University of Chicago Press.

Cheney, D. L., \& Seyfarth, R. M. (1997). Reconciliatory grunts by dominant female baboons influence victims' behavior. Animal Behaviour 54, 409-418.

Cheney, D. L., \& Seyfarth, R. M. (1998). Why monkeys don't have language. In G. Petersen (Ed.), The Tanner lectures on human values (Vol. 19, pp. 175-219). Salt Lake City: University of Utah Press.

Cheney, D. L., \& Seyfarth, R. M. (2007). Baboon metaphysics. Chicago: University of Chicago Press.

Cheney, D. L., Seyfarth, R. M., \& Silk, J. B. (1995). The role of grunts in reconciling opponents and facilitating interactions among adult female baboons. Animal Behaviour, 50, 249-257.

Clark, H. (1996). Using language. Cambridge, UK: Cambridge University Press.

de Waal, F. B. M., \& Ferrari, P. F. (2010). Towards a bottom-up perspective on animal and human cognition. Trends in Cognitive Science, 14, 201-207. doi:10.1016/j.tics.2010.03.003

Engh, A. L., Hoffmeier, R. R., Cheney, D. L., \& Seyfarth, R. M. (2006). Who, me? Can baboons infer the target of vocalizations? Animal Behaviour, 71, 381-387.

Ferrari, L., Bonini, L., \& Fogassi, L. (2009). From monkey mirror neurons to mirror related behaviours: Possible direct and indirect 
pathways. Philosophical Transactions of the Royal Society B, 364, 2311-2323.

Fischer, J., Metz, M., Cheney, D. L., \& Seyfarth, R. M. (2001). Baboon responses to graded bark variants. Animal Behaviour, 61, 925-931.

Fitch, T. (2010). The evolution of language. Cambridge: Cambridge University Press.

Freiwald, W., Tsao, D. Y., \& Livingston, M. S. (2009). A face feature space in the macaque temporal lobe. Nature Neuroscience, 12, 1187-1196.

Ghazanfar, A. A., \& Eliades, S. J. (2014). The neurobiology of primate communication. Current Opinion in Neurobiology, 28, 128-135.

Gifford, G. W., MacLean, K. A., Hauser, M. D., \& Cohen, Y. A. (2005). The neurophysiology of functionally meaningful categories: Macaque ventrolateral prefrontal cortex plays a critical role in spontaneous categorization of species-specific vocalizations. Journal of Cognitive Neuroscience, 17, 1471-1482.

Gilbey, I. C., Brent, L. J. N., Wroblewski, E. E., Rudicell, R., Hahn, B., Goodall, J., \& Pusey, A. E. (2013). Fitness benefits of coalitionary aggression in male chimpanzees. Behavioral Ecology and Sociobiology, 67, 373-381.

Glazko, G. V., \& Nei, M. (2003). Estimation of divergence times for major lineages of primate species. Molecular Biology and Evolution, 20, 424-434.

Hammerschmidt, K., \& Fischer, J. (2008). Constraints in primate vocal production. In U. Griebel \& K. Oller (Eds.), The evolution of communicative creativity: From fixed signals to contextual flexibility (pp. 93-120). Cambridge: MIT Press.

Hauser, M. D., Chomsky, N., \& Fitch, W. (2002). The faculty of language: What is it? Who has it? And how did it evolve? Science, 298, 1568-1579. doi:10.1126/science.298.5598.1569

Hockett, C. F. (1960). Logical considerations in the study of animal communication. In W. E. Lanyon \& W. N. Tavolga (Eds.), Animal sounds and communication (pp. 392-430). Washington, DC: American Institute of Biological Sciences.

Hurford, J. (2003). The neural basis of predicate-argument structure. Behavioral and Brain Science, 26, 261-316.

Hurford, J. (2007). The origins of meaning. Oxford: Oxford University Press.

Jackendoff, R. (1987). Consciousness and the computational mind. New York: Basic Books

Jackendoff, R. (1994). Patterns in the mind. New York: Basic Books.

Kanwisher, N., McDermott, J., \& Chun, M. M. (1997). The fusiform face area: A module in human extrastriate cortex specialized for face perception. Journal of Neuroscience, 17, 4302-4311.

Kirby, S. (1998). Fitness and the selective adaptation of language. In J. R. Hurford, M. Studdert-Kennedy, \& C. Knight (Eds.), Approaches to the evolution of language (pp. 359-383). Cambridge: Cambridge University Press.

Kitchen, D. M., Cheney, D. L., \& Seyfarth, R. M. (2005). Male chacma baboons (Papio hamadryas ursinus) discriminate loud call contests between rivals of different relative ranks. Animal Cognition, 8, 1-6.

Menzel, R. (2011). Navigation and communication in honeybees. In R. Menzel \& J. Fischer (Eds.), Animal thinking: Contemporary issues in comparative cognition (pp. 9-22). Cambridge: MIT Press.

Mitani, J. (2009). Male chimpanzees form enduring and equitable social bonds. Animal Behaviour, 77, 633-640.

Newmeyer, F. (1991). Functional explanations in linguistics and the origins of language. Language \& Communication, 11, 3-28.

Owren, M. J., Seyfarth, R. M., \& Cheney, D. L. (1997). The acoustic features of vowel-like grunt calls in chacma baboons (Papio cynocephalus ursinus): Implications for production processes and functions. Journal of the Acoustical Society of America, 101, 2951-2963. doi:10.1121/1.418523

Petkov, C. I., Kayser, C., Steudel, T., Whittingstall, K., Augath, M., \& Logothetis, N. K. (2008). A voice region in the monkey brain. Nature Neuroscience, 11, 367-374.
Pinker, S. (1994). The language instinct. New York: William Morrow.

Pinker, S., \& Bloom, P. (1990). Natural language and natural selection. Behavioral and Brain Sciences, 13, 713-738.

Schino, G., Tiddi, B., \& Polizzi di Sorrentino, E. (2006). Simultaneous classification by rank and kinship in Japanese macaques. Animal Behaviour, 71, 1069-1074.

Seyfarth, R. M., \& Cheney, D. L. (2010). Production, usage, and comprehension in animal vocalizations. Brain and Language, 115, 92 100.

Seyfarth, R. M., \& Cheney, D. L. (2012). The evolution of concepts about agents. In M. R. Banaji \& S. Gelman (Eds.), Navigating the social world: What infants, children, and other species can teach us (pp. 27-30). Oxford: Oxford University Press.

Seyfarth, R. M., \& Cheney, D. L. (2014a). The evolution of concepts about agents: Or, what do animals recognize when they recognize an individual? In E. Margolis (Ed.), The conceptual mind (pp. $57-$ 76). Cambridge: MIT Press.

Seyfarth, R. M., \& Cheney, D. L. (2014b). The evolution of language from social cognition. Current Opinion in Neurobiology, 28, 5-9. doi:10.1016/j.conb.2014.04.003

Seyfarth, R. M., \& Cheney, D. L. (2016). The origin of meaning in animal signals. Animal Behaviour.

Shlenker, P., Chemla, E., Schel, A. M., Fuller, J., Gautier, J.-P., Kuhn, J., ... Zuberbuhler, K. (2016). Formal monkey linguistics. Theoretical Linguistics.

Silk, J. B., Kaldor, E., \& Boyd, R. (2000). Cheap talk when interests conflict. Animal Behaviour, 59, 423-432.

Silk, J. B., Altmann, J., \& Alberts, S. C. (2006a). Social relationships among adult female baboons (Papio cynocephalus): I. Variation in the strength of social bonds. Behavioral Ecology and Sociobiology, 61, 183-195.

Silk, J. B., Altmann, J., \& Alberts, S. C. (2006b). Social relationships among adult female baboons (Papio cynocephalus): II. Variation in the quality and stability of social bonds. Behavioral Ecology and Sociobiology, 61, 197-204.

Silk, J. B., Beehner, J. C., Bergman, T., Crockford, C., Engh, A. L., Moscovice, L., ... Cheney, D. L. (2009). The benefits of social capital: Close social bonds among female baboons enhance offspring survival. Proceedings of the Royal Society B, 276, 30993014.

Silk, J. B., Beehner, J. C., Bergman, T., Crockford, C., Engh, A. L., Moscovice, L., \& Cheney, D. L. (2010). Strong and consistent social bonds enhance the longevity of female baboons. Current Biology, 20, 1359-1361.

Steiper, M. E., Young, N. M., \& Sukarna, T. Y. (2004). Genomic data support the hominoid slowdown and an early Oligocene estimate for the hominoid-cercopithecoid divergence. Proceedings of the National Academy of Sciences, 101, 17021-17026.

Tsao, D. Y., Freiwald, W. A., Tootell, R. B. H., \& Livingston, M. S. (2006). A cortical region consisting entirely of face-selective cells. Science, 311, 670-674. doi:10.1126/science.1119983

Wilson, B., Kikuchi, Y., Sun, L., Hunter, D., Dick, F., Smith, K., \& Petkov, C. I. (2015). Auditory sequence processing reveals evolutionarily conserved regions of frontal cortex in macaques and humans. Nature Communications, 6, 8901.

Wittig, R. M., Crockford, C., Ekberg, E., Seyfarth, R. M., \& Cheney, D. L. (2007). Kin-mediated reconciliation substitutes for direct reconciliation in female baboons. Proceedings of the Royal Society B, $274,1109-1115$.

Wittig, R. M., Crockford, C., Seyfarth, R. M., \& Cheney, D. L. (2007). Vocal alliances in chacma baboons. Behavioral Ecology and Sociobiology, 61, 899-909.

Worden, R. (1998). The evolution of language from social intelligence. In J. R. Hurford, M. Studdert-Kennedy, \& C. Knight (Eds.), Approaches to the evolution of language (pp. 148-168). Cambridge: Cambridge University Press. 